\title{
N-butanol and isobutanol as alternatives to gasoline: Comparison of port fuel injector characteristics
}

\author{
Michael Fenkl ${ }^{1, a}$, Martin Pechout ${ }^{2}$, Michal Vojtisek ${ }^{3}$ \\ ${ }^{1}$ Technical University of Liberec, Department of Power Engineering Equipment, Studentská 1402/2, Liberec I, Czech Republic \\ ${ }^{2}$ Technical University of Liberec, Department of Vehicles and Engines, Studentská 1402/2, Liberec I, Czech Republic \\ ${ }^{3}$ Czech Technical University in Prague, Center for Sustainable Mobility, Prilepska 1920, Roztoky u Prahy, Czech Republic
}

\begin{abstract}
The paper reports on an experimental investigation of the relationship between the pulse width of a gasoline engine port fuel injector and the quantity of the fuel injected when butanol is used as a fuel. Two isomers of butanol, n-butanol and isobutanol, are considered as potential candidates for renewable, locally produced fuels capable of serving as a drop-in replacement fuel for gasoline, as an alternative to ethanol which poses material compatibility and other drawbacks. While the injected quantity of fuel is typically a linear function of the time the injector coil is energized, the flow through the port fuel injector is complex, non ideal, and not necessarily laminar, and considering that butanol has much higher viscosity than gasoline, an experimental investigation was conducted. A production injector, coupled to a production fueling system, and driven by a pulse width generator was operated at various pulse lengths and frequencies, covering the range of engine rpm and loads on a car engine. The results suggest that at least at room temperature, the fueling rate remains to be a linear function of the pulse width for both n-butanol and isobutanol, and the volumes of fuel injected are comparable for gasoline and both butanol isomers.
\end{abstract}

\section{Introduction}

Finite amount of fossil energy resources, energy security and concerns about climate changes are some of the main drivers of the quest to replace these energy source with renewable, locally produced alternatives. This process also includes utilization of various fuels for internal combustion engines used in transportation and mobile machinery as a substitute of mostly used oil-based in transportation sectors.

Currently, ethanol blended into gasoline at various concentrations is the most utilized alternative for spark ignition engines. Unfortunately, ethanol exhibits some negative attributes, such as significantly lower energy content, hygroscopic behaviour and chemical aggresivity [1-5]. Also, broader consequences of fuel production need to be considered, as the current ethanol feedstock crops may compete with food production.

One promising alternative to ethanol is butanol - a four carbon alcohol, present in four isomers (n-butanol, 2-butanol, isobutanol, terc-butanol), out of which nbutanol and isobutanol (2-methyl-propan-1-ol) have be used as a fuel in spark ignition engines [6-8].

Key properties of n-butanol and isobutanol are compared with ethanol and gasoline in Table 1.
Table 1. Selected properties of gasoline and alcohol alternatives

\begin{tabular}{|c|c|c|c|c|}
\hline & Gasoline & N-butanol & $\begin{array}{l}\text { I s o - } \\
\text { butanol }\end{array}$ & Ethanol \\
\hline $\begin{array}{l}\text { Research octane } \\
\text { number (RON) }\end{array}$ & 95 & $\begin{array}{l}94[9-10] \\
-96[11]\end{array}$ & 113 & 110 \\
\hline $\begin{array}{l}\text { Density } \\
{\left[\mathrm{kg} \cdot \mathrm{m}^{-3}\right]}\end{array}$ & $\left.753^{* *}\right)$ & 810 & 806 & 790 \\
\hline $\begin{array}{l}\text { Lower heating } \\
\text { value }\left[\mathrm{MJ} \cdot \mathrm{kg}^{-1}\right]\end{array}$ & 42.9 & 33.3 & 33.3 & 26.8 \\
\hline $\begin{array}{l}\text { Volumetric lower } \\
\text { heating value } \\
{\left[\mathrm{MJ} \cdot \mathrm{dm}^{-3}\right]}\end{array}$ & 32.3 & 27.0 & 26.8 & 21.2 \\
\hline $\begin{array}{l}\text { Latent heat } \\
\text { of vaporization } \\
{\left[\mathrm{kJ} \cdot \mathrm{kg}^{-1}\right]}\end{array}$ & $380-500$ & $716[2]$ & 579 & 904 \\
\hline Chemical formula & $\begin{array}{l}\text { complex } \\
\text { mixture }\end{array}$ & $\mathrm{C}_{4} \mathrm{H}_{9} \mathrm{OH}$ & $\begin{array}{l}\mathrm{C}_{4} \mathrm{H}_{9} \mathrm{O} \\
\mathrm{H}\end{array}$ & $\begin{array}{l}\mathrm{C}_{2} \mathrm{H}_{5} \mathrm{O} \\
\mathrm{H}\end{array}$ \\
\hline $\begin{array}{l}\text { Mass share of C } \\
{[\%]}\end{array}$ & 86 & 65 & 65 & 52 \\
\hline $\begin{array}{l}\text { Mass share of } \mathrm{H} \\
{[\%]}\end{array}$ & 14 & 13.5 & 13.5 & 13 \\
\hline $\begin{array}{l}\text { Mass share of } \mathrm{O} \\
{[\%]}\end{array}$ & $0^{* *}$ & 21.5 & 21.5 & 35 \\
\hline Viscosity $[\mathrm{mPa} \cdot \mathrm{s}]$ & $0.4-0.8$ & 2.57 & 3.33 & 1.08 \\
\hline Boiling point $\left[{ }^{\circ} \mathrm{C}\right]$ & $\begin{array}{l}199 \\
\text { (FBP) }\end{array}$ & 118 & $\begin{array}{l}108 \\
{[12]}\end{array}$ & 78 \\
\hline Stoichimetric & 14.7 & 11.2 & 11.2 & 9.0 \\
\hline
\end{tabular}

air/fuel ratio

\footnotetext{
a Corresponding author: michael.fenkl@tul.cz
} 
Compared to ethanol, butanol has better miscibility with ordinary gasoline, is less corrosive, does not absorb water from ambient air, and is more compatible with the existing gasoline infrastructure. The energy density of butanol is significantly higher than ethanol. Potential drawbacks are that both butanol isomers exhibit significantly higher boiling temperature, viscosity and lover vapour pressure [13], which is important for running of cold engine.

On the other hand, production of both isomers - nbutanol and iso-butanol - from non-food crops such waste biomass, lignocelluloses etc. is more complicated to ethanol fermentation [2].

From the comparison of the properties of fuels it is apparent than the amount of injected fuel has to be increased when alcohol is added to maintain the desired typically stoichiometric - air to fuel ratio, which is necessary for the proper operation of the engine including its exhaust gas aftertreatment devices. Production ECUs (engine control units) generally have the capability of some degree of short-term and long-term adjustment of the fuel injection pulse width, intended to serve as a compensation of variations in the composition and other properties of the fuel and in the condition and general working of the engine. Such capacity has not, however, been intended to cover, for example, a rather substantial increase in the fuel delivery rates when switching from gasoline to ethanol. The use of high concentrations of ethanol generally requires either an ECU designed for such fuel, or the installation of an auxiliary control unit, the function of which is often limited to the prolongation of the fuel injector pulse width.

The prolongation of the fuel injector pulse width is not necessarily simply a matter of multiplying the injector opening time with the ratio of the volumetric energy densities of traditional and alternative fuel. The steadystate flow through an open injector is also affected by the fuel viscosity. Also, rather complicated dynamic effect during injector opening and closing need to be considered when calculating the injector pulse width (the time for which the injector coil is energized) necessary to deliver the desired quantity of the fuel.

The effect on replacing gasoline with either n-butanol or isobutanol on the relationship between the fuel injector pulse width and the quantity of the fuel delivered is considered in this work.

In general, for a laminar flow, the effect of fuel viscosity on the injector flow rate, everything else being equal, is given by Hagen-Poiseuille equation [14]:

$$
\dot{V}=\frac{\pi D^{4} \Delta p}{128 \mu L}
$$

where $D$ is the diameter and $L$ is the length of the pipe, $p$ is pressure loss across the pipe, and $\mu$ is the dynamic viscosity of the fluid.

Unfortunately in injectors for engines with multipoint injection the flow passes through a thin orifice, which is too short to have purely laminar flow, and as a result, the Hagen-Poiseuille equation results in unphysically high flow rates. The flow is bounded by Bernoulli's principle, under less restrictive conditions [15]:

$$
\dot{V}_{\max }=\pi R^{2} \cdot \sqrt{\frac{2 \cdot \Delta p}{\rho}} .
$$

The Reynolds number in a port injection spark ignition engine injector was reported to be on the order of 10-100 [16], depending on the fuel composition and temperature. While such a range of $\mathrm{Re}$ typically represents laminar flow through a pipe [17], not knowing the precise geometry of the injector, which is rather complex, the flow through the injector may lie in the transition region between laminar and turbulent flow [1819]. Further uncertainties are expected during the injector opening and closing period.

Therefore, while no surprising non-linearities have been found with ethanol, and the volumes of the fuel injected during a given pulse width were reported not to differ more than $10 \%$ between ethanol and gasoline [20$21]$, the considerably higher viscosity of both n-butanol and isobutanol as compared to either gasoline or ethanol (see Table 1) complicates the development of a simple method describing the flow through the injector as a function of fuel properties.

Therefore, an experimental approach, also including potential effect of used fuel on pressure reducing valve and rail pressure, has been chosen to elucidate the effect of replacing gasoline with n-butanol or isobutanol on the relationship between the fuel injector pulse width and the energy content of the fuel delivered. As an added value, such determination could allow for determination of a correction factor for the ECU reported fuel consumption when using butanol as a fuel.

\section{Experimental}

\subsection{Injection fuel system}

The injector characteristics were examined on an inhouse produced experimental apparatus consisting of a production fuel injector fed from a production fuel supply system. The injector was driven by a pulse generator and was injecting into a graduated cylinder. The scheme of this apparatus is shown on Figure 1.

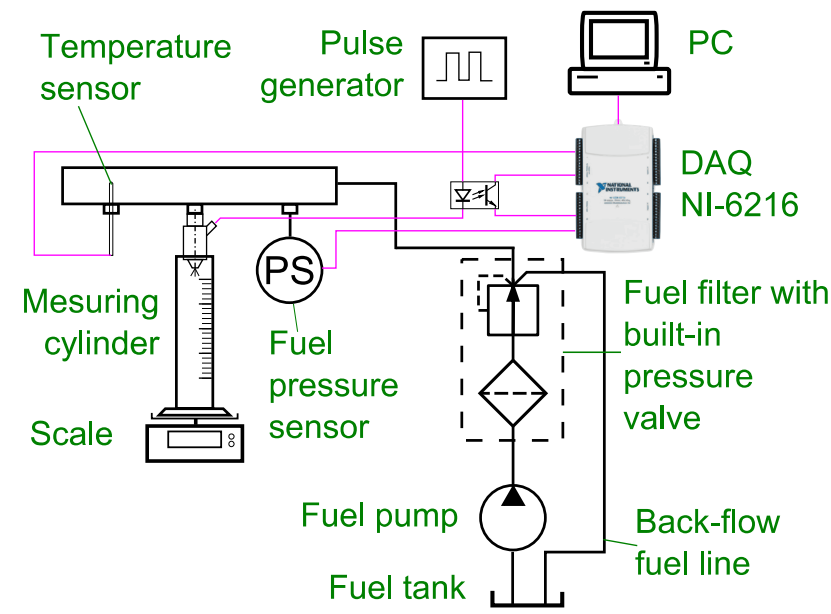

Figure 1. Scheme of injection and data acquisition system 
Fuel is supplied by the fuel pump through filter holder with integrated output pressure regulator $(4 \mathrm{bar})$ into a standard fuel rail, which has only one of the middle ports coupled to an injector. All parts were from a Volkswagen EA-111 series gasoline engine. The remaining ports were fitted with a thermocouple to measure temperature of the fuel in the rail, by a pressure sensor to record possible injection pressure changes due to different fuels properties, and by a plug.

Pressure sensor voltage output and thermocouple signal were sensed by data acquisition system (NI-6216). As the used pulse width generator does not allow setting of desired count of pulses, an A/D converter was connected using an optocoupler to ensure counting count of injection pulses. The mass accumulated over several thousands of pulses (each pulse corresponding to tens of $\mathrm{mg}$ of fuel) has been determined by a laboratory scale (Sartorius, resolution $0.1 \mathrm{~g}$ ) and divided by the number of pulses to obtain the mean amount of injected fuel per one burst.

\subsection{Injection conditions and data processing}

Technical grade N-butanol and isobutanol, commonly sold for industrial use (such as solvents) were obtained from industrial distributors (Chemap, Dašice, CZ, and Chemlogistic, Pardubice, CZ). Non-oxygenated gasoline was obtained from the state-owned supplier (Cepro).

Combinations of injection pulse frequency corresponding to engine rpm 2000 to $5000 \mathrm{rpm}$ with 1000 rpm step and fuel injection pulse width of 5, 10, 15 and $20 \mathrm{~ms}$, and $3 \mathrm{~ms}$ at $1000 \mathrm{rpm}$ to represent idling conditions, were selected based on real engine characteristics. All combinations were repeated three times to address the procedure repeatability.

Captured fuel injection voltage signal has been analysed and fuel injection pulses were counted using rising edge detection. The mean cycle based amount of injected fuel has been obtained as the ratio of total injected mass to the number of pulses.

\section{Results and discussion}

The mean mass of injected fuel as a function of frequency at a given fuel injection pulse width are displayed on Fig. 2 and the mean mass of injected fuel as a function of rpm are shown on Figure 3.

The data obtained show very good repeatability. It is clearly visible that the injected amount is nearly independent on the injection frequency. This is the case notably for both butanol isomers. For gasoline, where some dependency on the pulse frequency has been observed, the primarily lower fuel quantity at lower rpm (lower frequency) is possibly attributable to higher evaporation loses as a result of significantly higher vapour pressure of gasoline.

The amount of injected fuel has been close for both butanol isomers where amount of injected iso-butanol was up to $1 \%$ higher.
From the elementary Bernoulli equation based theoretical flow speed of

$$
c=\sqrt{\frac{2 \cdot\left(p_{R A I L}-p_{I M A}\right)}{\rho}}
$$

based on pressure difference inside the fuel rail $\boldsymbol{p}_{\boldsymbol{R} A I L}$, pressure in intake manifold (or ambient pressure during this experiments) $\boldsymbol{p}_{I M A}$ and fuel density $\rho$ a theoretical ratios of both injected volume and mass at a constant injection pressure, injection duration and duration of noninjecting par can be derived as a function of fuel density:

$$
\frac{V_{B u}}{V_{g a s}}=\sqrt{\frac{\rho_{g a s}}{\rho_{B u}}} ; \frac{m_{B u}}{m_{g a s}}=\sqrt{\frac{\rho_{B u}}{\rho_{g a s}}} .
$$

Using this hypothesis the ratio of injected butanol mass to gasoline mass should be, using the densities in Table 1, approximately 1.037 for $n$-butanol and 1.035 for isobutanol. The experimental results show mean values of 1.084 for isobutanol and 1.074 for n-butanol, with rather low differences among the three tests of about $1 \%$, but more considerable differences among different pulse frequencies.

Using a purely volumetric metering hypothesis, under which the volume of the fuel injected is independent of the fuel properties, the ratios of fuel mass should be equal to the ratios of fuel densities, which are 1.096 for n-butanol and 1.088 for isobutanol. The density ratios are only about $1 \%$ lower than the observed ratios of fuel mass injected. It is therefore quite remarkable that metering of the all the fuels can be simplified as volumetric with error of total injected mass about $1 \%$, which is within the experimental uncertainties.
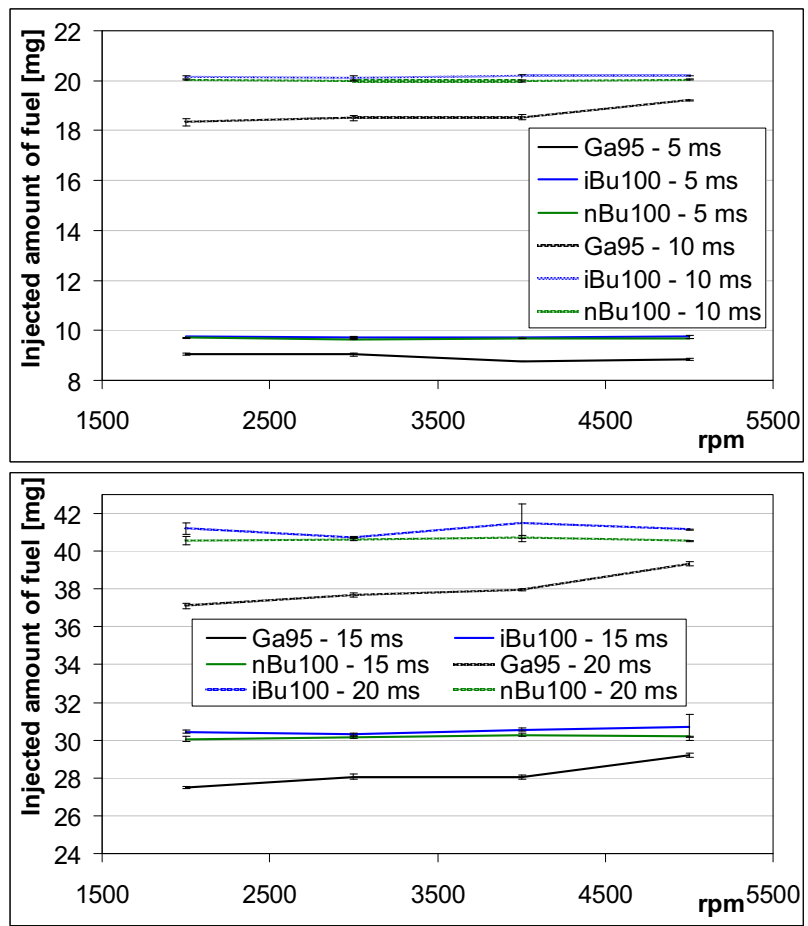

Figure 2. Effect of used fuel on mass amount of injected fuel for various fuel injection pulse width and rpm. 

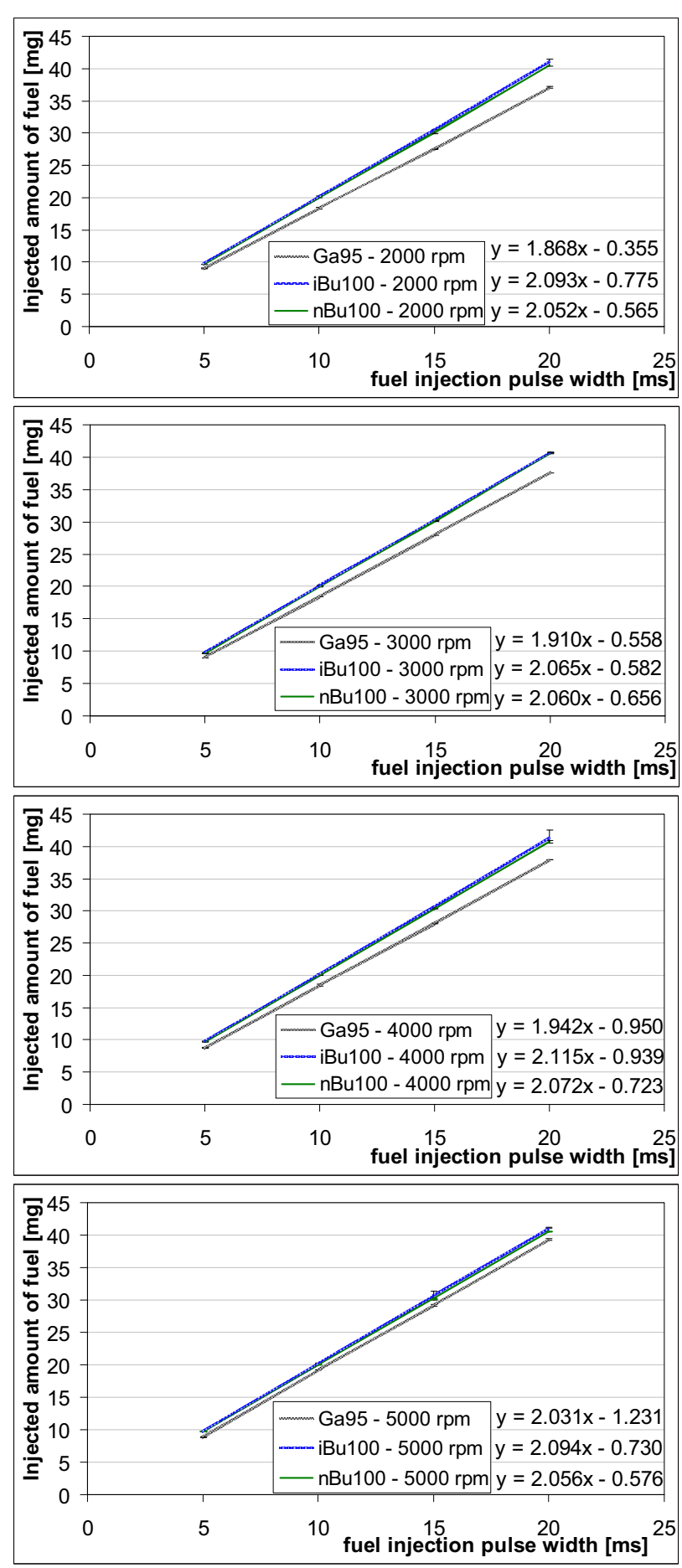

Figure 3. Effect of used fuel on mass amount of injected fuel for various fuel injection pulse width and rpm.

Somewhat higher increase of injected mass has been observed during injection conditions typical for engine idle (approx 3ms injection duration at frequency corresponding $1000 \mathrm{rpm}$, Figure 4). These increases were about $12.5 \%$ for iso-butanol and $11.4 \%$ for $n$-butanol.

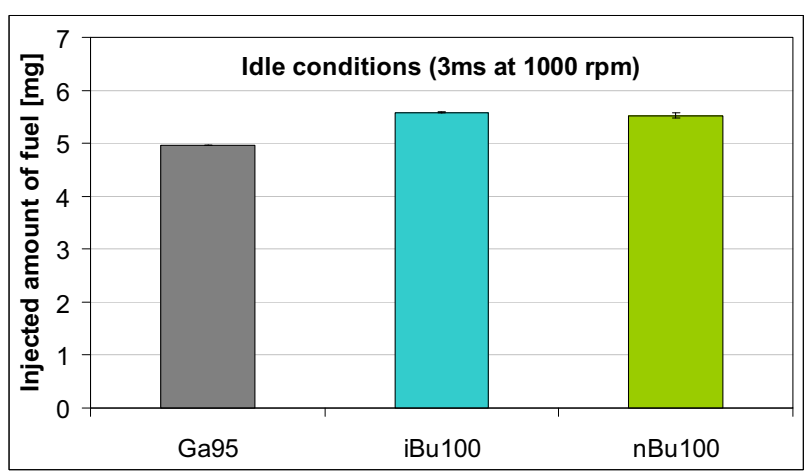

Figure 4. Effect of used fuel on mass amount of injected fuel at idling conditions.

To investigate this difference, the injection time "overhead", or the length of the non-effective period, was investigated. The overhead time was determined by extrapolation of the injected amount to the zero quantity of the fuel injected using linear regression coefficients (Fig. 3). This consideration resulted in values between 0.3 and $0.4 \mathrm{~ms}$ without remarkable dependency on rpm or the fuel used.

Based on stochiometric air to fuel ratio of gasoline and both butanol isomers (see Table 1), to maintain the same air-fuel ratio, the mass amount should be increased by about $31 \%$ when gasoline is replaced by butanol while $63 \%$ increase is necessary when neat ethanol is to be used. Considering that the injected mass increased by about $8.4 \%$ for $n$-butanol and $7.4 \%$ for isobutanol due to higher butanol density, an additional increase of only about $23 \%$ is needed, compared to approximately $52 \%$ for ethanol.

\section{Conclusions}

The relationship between the frequency and length of the fuel injector pulse width and the quantity of the fuel delivered has been tested for two candidate alternative fuels, n-butanol and isobutanol, and compared to gasoline. The testing was performed on a production port fuel injector coupled to production fuel system (fuel tank, fuel pump, fuel rail with pressure regulator), and driven by a pulse width generator.

The experimental data showed very good repeatability. Results showed minimum dependency of injected mass on rpm, especially for both butanol isomers, so the dependency of injected fuel mass on fuel injector pulse width is following a linear trend.

From extrapolation of the linear trend the noneffective part of injection period has been derived with no significant dependency on injection frequency and used fuel. As a result, this method poses a simple way how to determine the fuel consumption during engine non-steady state typical for real-world engine operation using onboard diagnostic interface.

Changes in the injected mass have shown that the simplified approach assuming volumetric metering generates inaccuracy about $1 \%$ when gasoline is replaced with neat butanol (either n-butanol or isobutanol). 
Estimation of volumetric metering gives more accurate values for injected mass change compared to a simple model based on Bernoulli equation. The volumetric assumption gives a prediction error about $1 \%$ which is sufficiently small for practical usage.

\section{References}

1. R. Cascone, Chem. Eng. Prog. 104, p. S4-S9, (2008)

2. P. Patakova, D. Maxa, M. Rychtera, L. Linhova et al., M.A.D.S., ISBN 978-953-307-480-1, p. 243-266, InTech, Rijeka, Croatia, (2011)

3. B. Jones, G. Mead, P. Steevens, "The Effects of E20 on Plastic Automotive Fuel System Components" Tech. Rep. 20082/21/2008, Minnesota Center for Automotive Research, (2008).

4. B. Bailey, "Performance of Ethanol as a Transportation Fuel," In: Handbook on Bioethanol: Production and Utilization. Edited by Wyman C. E. Online at http://infohouse.p2ric.org/ref/36/35015.pdf (accessed October 10, 2015).

5. EPA (Environment Protection Agency U.S.), "1Butanol as a Gasoline Blending Bio-component," BP, Mobile Sources, Technical Review Subcommittee, March 28, (2007), http://nsdi.epa.gov/air/caaac/mstrs/March2007/Wolf. pdf.

6. S. Szwaja, J. D. Naber, Fuel, 89, Issue 7, p. 15731582, (2010), doi:10.1016/j.fuel.2009.08.043.

7. F. N. Alasfour, Int. J. of Energy Research, 21, Issue 1, p. 21-30, (1997), doi:10.1002/(SICI)1099114X(199701)21:1<21::AID-ER231>3.0.CO;2-K.

8. T. Wallner, A. Ickes, N. Shidore, "Impact of ethanol and butanol as oxygenates on SIDI engine efficiency and emissions using steady-state and transient test procedures," DEER 2010, Detroit, Michigan, September 27-30, (2010).

9. A. Cairns, A. Todd, P. Aleiferis, N. Fraser, et al., "A Study of Alcohol Blended Fuels in an Unthrottled Single Cylinder Spark Ignition Engine," SAE Technical Paper 2010-01-0618, 17, (2010), doi:10.4271/2010-01-0618

10. M. Thewes, M. Müther, A. Brassat, S. Pischinger et al., "Analysis of the Effect of Bio-Fuels on the Combustion in a Downsized DI SI Engine," SAE Int. J. Fuels Lubr. 5(1), p.274-288, (2011), doi:10.4271/2011-01-1991 .

11. S. Merola, C. Tornatore, G. Valentino, L. Marchitto, et al., "Optical Investigation of the Effect on the Combustion Process of Butanol-Gasoline Blend in a PFI SI Boosted Engine," SAE Technical Paper 201124-0057, 15, (2011), doi:10.4271/2011-24-0057.

12. Chemistry Webbook. National Institute of Standards and Technology. Online at http://webbook.nist.gov.

13. V. F. Andersen, J. E. Andersen, T. J. Wallington, S. A. Mueller, et al.," "Vapor Pressures of AlcoholGasoline Blends," Energy \& Fuels, 24, p. 36473654, (2010), doi:10.1021/ef100254w

14. S. P. Sutera, R. Skalak, "The history of Poiseuille's law". Annual Review of Fluid Mechanics 25: pp. 119 (1993).
15. C. O. Bennett, J. E. Myers, Momentum, Heat, and Mass Transfer, McGraw-Hill (1962).

16. P. G. Aleiferis, J. Serras-Pereira, Z. van Romunde, J. Caine, M. Wirth, Combustion and Flame 157, pp. 735-756, (2010).

17. J. P. Holman, Heat Transfer, p. 207, (2002).

18. M. C. Potter, D. C. Wiggert, B. H. Ramadan, T. I. P. Shih, Mechanics of fluids (Fourth edition. ed.). Cengage Learning (2012).

19. D. Kolokotronis, Y. Hardalupas, A. Taylor, P. Aleiferis et al.: "Experimental Investigation of Cavitation in Gasoline Injectors", SAE Technical Paper 2010-01-1500, 23, (2010), doi:10.4271/201001-1500.

20. T. N. C. Anand, A. Madan Mohan, R. V. Ravikrishna, "Spray characterization of gasolineethanol blends from a multi-hole port.", Fuel, 102, $10,(2012)$

21. J. Gao, D. Jiang, Z. Huang, "Spray properties of alternative fuels: A comparative analysis of ethanolgasoline blends and gasoline.”, Fuel, 86, 5, (2007)

\section{Acknowledgements}

The work of M.P. and material expenses were covered by the Student Grant Competition of the Technical University of Liberec, grant 21013 "Possibilities of utilizing higher alcohols for fast gasoline replacement." The work of M.V. was funded by the Czech Ministry of Education, Youth and Sports program NPU I (LO), project "Development of Vehicle Center of Sustainable Mobility" (LO1311).

The work of M.F. and material expenses were covered by the Student Grant Competition of the Technical University of Liberec, grant 21000. 